University of Nebraska - Lincoln

DigitalCommons@University of Nebraska - Lincoln

USDA National Wildlife Research Center - Staff Publications
U.S. Department of Agriculture: Animal and Plant Health Inspection Service

$7-5-2002$

\title{
Estimating deer damage losses in cabbage
}

Richard M. Engeman

USDA-APHIS-Wildlife Services, s_r100@yahoo.com

Brian K. Maedke

USDA APHIS Wildlife Services

Scott F. Beckerman

USDA APHIS Wildlife Services, Sc.Beckerman@aphis.usda.gov

Follow this and additional works at: https://digitalcommons.unl.edu/icwdm_usdanwrc

Part of the Environmental Sciences Commons

Engeman, Richard M.; Maedke, Brian K.; and Beckerman, Scott F., "Estimating deer damage losses in cabbage" (2002). USDA National Wildlife Research Center - Staff Publications. 484.

https://digitalcommons.unl.edu/icwdm_usdanwrc/484

This Article is brought to you for free and open access by the U.S. Department of Agriculture: Animal and Plant Health Inspection Service at DigitalCommons@University of Nebraska - Lincoln. It has been accepted for inclusion in USDA National Wildlife Research Center - Staff Publications by an authorized administrator of DigitalCommons@University of Nebraska - Lincoln. 


\title{
Estimating deer damage losses in cabbage
}

\author{
Richard M. Engeman ${ }^{\mathrm{a}, *}$, Brian K. Maedke ${ }^{\mathrm{b}}$, Scott F. Beckerman ${ }^{\mathrm{b}}$

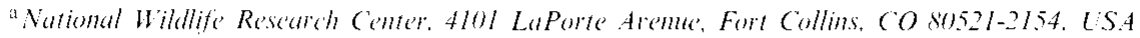

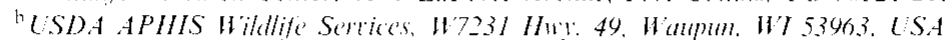

\begin{abstract}
A standardized procedure for estimating deer damage in cabbage is used to settle claims for compensation of losses in the state of Wisconsin. By completely enumerating all damaged heads of cabbage in a field, we validated the standard procedure for accuracy. The general paradigm used for assessing losses requires a subjective examination of the field to define strata with and without damage, obtaining representative samples of undamaged heads in each strata with 3 quadrats, then converting the difference in density of undamaged heads between strata into an estimate of damage for the entire field. Weighing a sample of undamaged heads allows estimation of the total weight lost to deer damage and the calculation of a cost value. We also applied a form of variable area transect (VAT) sampling without stratification of the field to test whether this less labor-intensive sampling method could produce adequate loss estimates. The field had 1265 commercial-quality cabbage heads damaged by decr. The standard assessment procedure estimated 1330 damaged heads, whereas V'AT sampling estimated at most 346 damaged heads. We concluded that the standard procedure was quite accurate, and we suggested modifications to the VAT sampling that might lead to greater accuracy in future trials. (1) 2002 Elsevier Science Ltd. All rights reserved.
\end{abstract}

Kelvords: Damage assessment; Quadrat sampling: Variable area transect; Vertebrate pest damage

\section{Introduction}

Assessment of animal damage to crops is integral to any practical damage reduction program. Estimation of damage is essential for cconomic evaluation of the problem, is used to predict cumulative damage (and, hence, the need for control) in the growing cycle of a crop, is the measure of efficacy of control efforts, and in some situations is used for determining the amounts for claims to a government agency in compensation for losses to "publicly owned" animals. However, the sampling effort required to produce accurate estimates is balanced by the labor and logistics required to acquire the samples.

We consider here the estimation of deer damage to a relatively high-value crop, cabbage. Deer can cause damage to cabbage throughout a growing season, but any observable damage to a head at harvest is commercially unacceptable. By fully (and laboriously) enumerating all deer damaged heads of cabbage within a ficld, we assessed the accuracy of the estimation methods used for wildlife compensation claims in the state of Wisconsin (Wisconsin Department of Natural Resources, 1998). Estimation of deer damage to cabbage follows a general paradigm for estimating wildlife

\footnotetext{
* Corresponding author. Tel.: 1-970-266-6091: fax: 1-970-266-6089.

E-mail address: richard.m.engeman (a usda.gov (R.M. Engeman).
}

damage to crops; (1) identify zones within a field receiving damage, (2) measure the area encompassed by the damaged stratum, (3) sample (usually using quadrats or plots) undamaged and damaged areas for production, (4) estimate the difference in average production between samples from damaged and undamaged strata and project the total damage for the entire field. This procedure has a number of potential difficulties that could lead to over- or underestimation of losses due to animal damage, including (1) the subjectivity in defining the damaged and undamaged strata within the field, (2) the adequacy of sample size in each strata, (3) the adequacy of sample plot size, (4) the restrictions on the amount of information collected due to limits on time and labor required to carry out the methods. With such potential pitfalls to accurately estimate damage, we wished to validate the accuracy of the existing damage estimation method, especially since it is used for compensation of wildlife damage claims.

Besides the issue of evaluating accuracy for a standard paradigm, we also considered the issue of in-field labor required to produce damage estimates. In particular, we wanted to achieve accurate damage estimates, but eliminate the time and labor required in steps 1 and 2 above of the general procedure where a damaged stratum must be identified and measured for area. We also wanted to combine the third and fourth steps such that losses throughout the 
field are sampled without first having defined damaged and undamaged zones.

Many attempts have been made to develop improved methods for estimating the density of immobile objects, such as points of animal damage (e.g. Diggle. 1975: Kendall and Moran, 1963; Pollard, 1971). Although quadrat or plot method sampling is well-known to produce unbiased estimates (e.g., Engeman et al., 1994), it can be labor intensive, especially when objects are sparse, unevenly distributed, or otherwise difficult to locate. Variable area transect (VAT) sampling (Parker, 1979) was identified as an easy-to-apply sampling method that produced high-quality density estimates (Engeman et al., 1994). VAT sampling involves measuring the distance traveled along a fixed-width strip transect in a random direction from random start points until the $r$ th $(r>2)$ population member (damage point) is encountered. VAT estimation also has been optimized for the number of population members to encounter from each random starting point, with $r=6$ providing an optimal balance between quality of estimation and labor in the field (Engeman and Sugihara, 1998). In addition to evaluating the standard procedures, we also considered VAT sampling as a labor-saving alternative method.

\section{Methods}

Our study took place in September, 1999 in Outagamie County, Wisconsin. To assess the methods, we selected a 0.73 ha cabbage field exhibiting deer damage. The cabbage in our study field had been grown for use in the production of sauerkraut (the least valuable cabbage). The field was $55.2 \mathrm{~m}$ wide and $132.0 \mathrm{~m}$ long, with 70 rows $(0.79 \mathrm{~m}$ row spacing).

We applied the procedures used as a standard for damage compensation claims in Wisconsin for assessing deer damage to cabbage (Wisconsin Department of Natural Resources, 1998). Damage estimates were made just prior to harvest by examining the complete field and identifying the damaged portions. The area of the damaged stratum was calculated with the aid of aerial photographs. The damaged and undamaged strata then were sampled with 30.004-ha quadrats. Within each quadrat, all undamaged, commercially acceptable heads were counted. Five undamaged heads from the field were randomly selected, harvested, and weighed to provide an average head weight. The difference in weight per hectare for the damaged and undamaged strata was multiplied by the area of the damaged strata to produce an estimate of total weight lost for the field.

VAT sampling was applied by randomly selecting the first start point within the first tenth of the field (in terms of number of rows). From each start point, the observer walked in a random direction (up or down the row) until six damaged cabbage heads were located. If the observer reached the end of the row before observing six damaged heads, he wrapped around to the next row, walking back in the opposite direction. After observing six damaged heads, another start point was randomly selected in the next one tenth of the rows in the field from the endpoint of the just-completed observation. This continued until 10 random start points had been used or no more room in the field was left to sample. The distance from the start point to the 3 rd- 6 th damaged heads was recorded to allow for four different VAT estimates to be calculated (based on $r=3-6$ ), in the event that an $r<6$ provided adequate estimation. Density of damaged heads was calculated according to the formula: $(n r-1) /\left(w \Sigma d_{i}\right)$, where $n$ was the sample size, $w$ was the row width in the field, and $d_{i}$ was the distance from the $i$ th random start point to the $r$ th damaged head (Parker, 1979).

To determine the accuracy of the estimation methods, all rows of the field were walked and each damaged cabbage head identified. Thus, the exact number of heads lost to deer damage for the field was known. To translate numbers lost into yield in weight lost, five undamaged cabbage heads were selected at random from the field and weighed. Their average head weight was used to calculate losses for the field on a weight basis.

\section{Results}

The complete census of all cabbage heads in the field revealed that 1265 had been damaged by deer. The average weight of the undamaged heads was $4.38 \mathrm{~kg}$, or 5.54 metric tons for the field.

Of the 0.73 total hectare of the field, the strata with deer damage comprised 0.40 ha. The number of undamaged cabbage heads per 0.004-ha plot in the undamaged strata was 83.0 versus 69.7 for the plots in the damaged strata, for a difference of 13.3 heads per plot. This translates to an estimate of 1330 heads lost to deer damage for the field, or 5.83 metric tons. This represents a difference of only 0.29 metric tons from the actual amount for the entire field. At the time of the study, the market price of cabbage for saucrkraut production was approximately $\$ 43 /$ metric ton, yielding an overestimate in the cost of decr damage for the field of only $\$ 12.47$.

VAT estimates when using $r=3,4,5,6$ yielded densities of deer-damaged heads of $473.5,419.7,430.3$ and 398.2 heads/ha, respectively, or 346,306,314, 291 damaged heads in the field. At $4.38 \mathrm{~kg} /$ head this results in weight loss estimates of $1.51,1.34,1.37$, and 1.27 metric tons, respectively, lost to decr damage. Thus, this sampling method accounted for approximately one-quarter of the damage, which would translate into an underpayment of about $\$ 180$ for the field.

\section{Discussion}

Valuable information was gained on the currently applied estimation method in that it appears quite accurate, despite small sample sizes and the potential influence from the 
subjectivity in stratifying the field into damaged and undamaged zones. On the other hand, based on results from theoretical simulation studies, we expected the VAT sampling and estimation to produce substantially more accurate results.

To consider why such a disparity would exist, we examined differences between sampling our field and sampling the theoretical populations in simulation studies (Engeman et al., 1994; Engeman and Sugihara, 1998). First, members of the simulated populations (damaged cabbage heads for our purposes ) could have been situated anywhere in the sampled area, whereas damaged heads in our field could only be found in distinct rows. Secondly, as a consequence, VAT sampling for the simulated populations could go in a random direction, but in our field of cabbage sampling could only go up or down a row.

Intuitively, these considerations do not seem to account for the failure of VAT sampling to produce accurate estimates for the cabbage field, in contrast to results from very extensive theoretical simulations. Therefore, we must also consider the spatial pattern of the deer damage in the cabbage field and the effects this might have had on our application of VAT sampling. As is typical, the deer damage to cabbage heads was highly aggregated (clumped) near the field edges. This type of spatial pattern has long been obscrved to pose challenges for distance sampling methods (Batcheler, 1971; Kendall and Moran, 1963; Pielou, 1959). Our data indicate that the severity of clumping caused the inter-clump distances to be more heavily sampled than the within clump distances. This would lead to underestimation of the density of damaged heads in the field. However, VAT sampling has been shown to overcome problems with aggregation (Engeman and Sugihara, 1998). One potential solution to this problem would be to simultaneously examine two rows for damage. This would require less walking in the field than when just examining one row and it likely would better sample the distances between damaged heads within an aggregation of damaged heads. That in turn may produce more accurate density estimates of damaged heads in the field.
In conclusion, the sampling and estimation procedure currently in place gave an accurate assessment of deer damage to the cabbage field. VAT sampling, as applied, did not produce acceptable results. However, in light of the considerable savings in effort in the field and that VAT sampling has been successful in other scenarios, further testing of the VAT sampling is merited, as another formulation still may produce a methodology with accuracy comparable to the standard method.

\section{Acknowledgements}

We thank M. Fall, M. Pipas and G. Witmer for their valuable reviews of the manuscript.

\section{References}

Batcheler. C.L., 1971. Estimation of density from a sample of joint point and nearest neighbour distances. Ecology 53, 703-709.

Diggle, P.J., 1975. Robust density estimation using distance methods. Biometrika 62, 39-48.

Engeman, R.M., Sugihara, R.T., 1998. Optimization of variable area transect sampling using Monte Carlo simulation. Ecology 79, 14251434

Engeman, R.M., Sugihara, R.T., Pank, L.F., Dusenberry, W.E., 1994. A comparison of plotless density estimators using Monte Carlo simulation. Ecology 75, 1769-1779.

Kendall, M.G., Moran, P.A.P., 1963. Geometrical Probability. Giriffin, London, 125p.

Parker, K.R.. 1979. Density estimation by variable area transect. Journal of Wildlife Management 43, 484-492.

Pielou, E.C., 1959. The use of point to plant distances in the study of the pattern of plant populations. Journal of Ecology 47, 607-613.

Pollard, J.H., 1971. On distance estimators of density in randomly distributed forests. Biometrics 27, 991-1002.

Wisconsin Department of Natural Resources, 1998. Wildlife Damage Abatement and Claims Program Technical Manual, Vol. 2, Field Handbook. Wisconsin Department of Natural Resources, Madison, WI, $153 \mathrm{pp}$. 